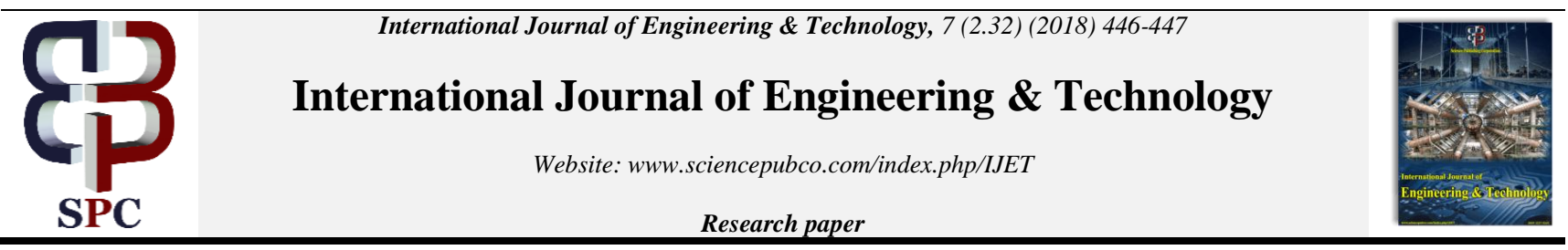

\title{
Controlling Home Appliances Using IOT
}

\author{
V.Rama Krishna ${ }^{1}$, Y.Prem Satish ${ }^{2}$, N.Raj Kumar ${ }^{3}$, E.Sai Keerthie ${ }^{4}$ \\ ${ }^{1,2,3,4}$ Dept of CSE, K L E F,Vaddeswaram, India \\ *Corresponding author E-mail: vramakrishna@kluniversity.in
}

\begin{abstract}
These days, huge consideration is being given to IOT in many fields. It chiefly manages the correspondence between a few electrical gadgets. The IOT is encountering quick reception in the public, from mechanical to home applications. We can influence gadgets to convey through an interconnection organize. We can apply IOT in many fields. Here, we are for the mostly focusing on controlling Home Machines. As per condition, consequently, the gadgets can do their errands. With the improvement of the social economy, a number of machines which always increases have been exhibited in a house. It is an issue that how to oversee and control these apex different machines proficiently and advantageously in order to accomplish more agreeable, security and solid space at home. In current Venture, We will manage a few parts of the IOT in Home Machines controlling.
\end{abstract}

Keywords:IOT, Home Automation, Smart Home, Smart Phone, Raspberry Pi board.

\section{Introduction}

These days, huge consideration is being given to IOT in many fields. By using Internet of things we can control devices like fan, PC, circuits, lights and home security. It decreases human efforts. The target of internet of things is to help the physically handicapped people and old people to manage the electrical appliances and security systems. We can control the IOT devices through WIFI (or) Router. It is a low cost \& valuable in critical circumstances.Contolling home appliances using IoT uses computer or devices to control basic home functions and can be accessed from anywhere in the world. The devices which are used in the process are uniquely identifiable through its embedded system.

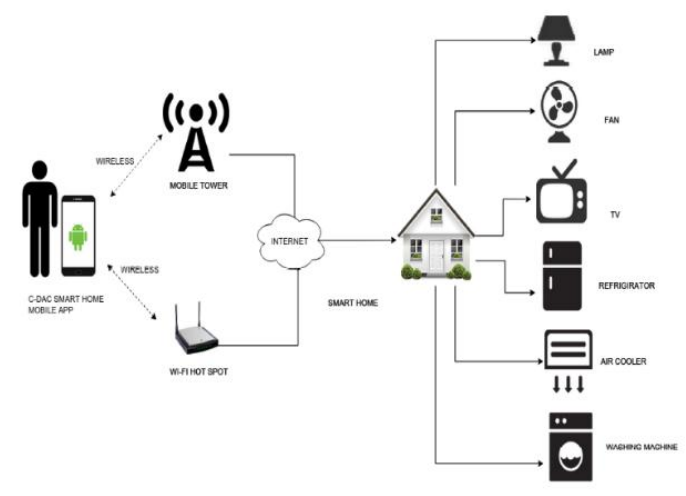

\section{Related Work}

We are living in the domain of automation where most of the structures are getting computerized, for example, modern day mechanization, homes and distinctive business areas. Home automation Systems are advancing to the automation forms were in human endeavors are required by the hardware types of gear to work different loads in homes. It includes programs that can control home appliances utilizing distinctive innovations and controllers over desktops, portable PCs, advanced mobile phones or tablets.

The Raspberry pi is like a cross between a computer and microcontroller. It is solitary pc board which can be used in implementing IOT applications. One advantage of using Raspberry over Arduino is ...Arduino runs only one program at a time. Since Arduino and Raspberry $\mathrm{Pi}$ are the most popular computing option for IOT applications, when comparing Arduino and Raspberry Pi boards, A Raspberry $\mathrm{Pi}$ is the general-purpose computer, which usually supports Linux operating system which also has the ability to run many programs at once. Whereas an Arduino can run only one program at a time. When it comes to the usage of full-fledged computer Raspberry Pi is the best choice and also it helps us to drive complicated robot, does intense calculations as for the purpose of encryption or bitcoin and the multitask can be performed.

Raspberry Pi is very convenient to connect with the internet and the entire Linux software stack will be available. And the most important point here is the Raspberry Pi code can be written in a variety of languages. Both raspberry pi and Arduino vary in many ways. The most important factor or advantage of using the latest version of raspberry pi instead of Arduino is, there is inbuilt Wi$\mathrm{Fi}$, which helps us to overcome the struggles of internet connectivity issues. Below is an elaborated comparison between both.The raspberry pi accompanies an arrangement of the open source advancements, That is a correspondence and interactive media web innovations.

Also, different interfaces for the other outside devices. And more, It requires mass accumulating, for that reason, we need to use SD streak memory card. Raspberry pi uses SD card to boot Here are some differences between Arduino and Raspberry pi: 


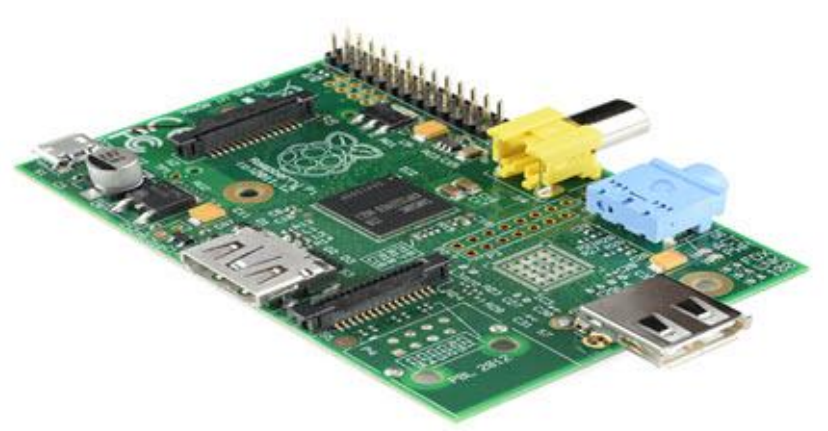

\section{Proposed System}

Below fig explains the various layers in IOT

Architecture. The system consists of a computer server with an internet connection, a modem connecting the server to external network, a raspberry pi microcontroller with a hardwired application associated with gadgets. The model framework underpins two-level devices that only need to be turned on or turned off.

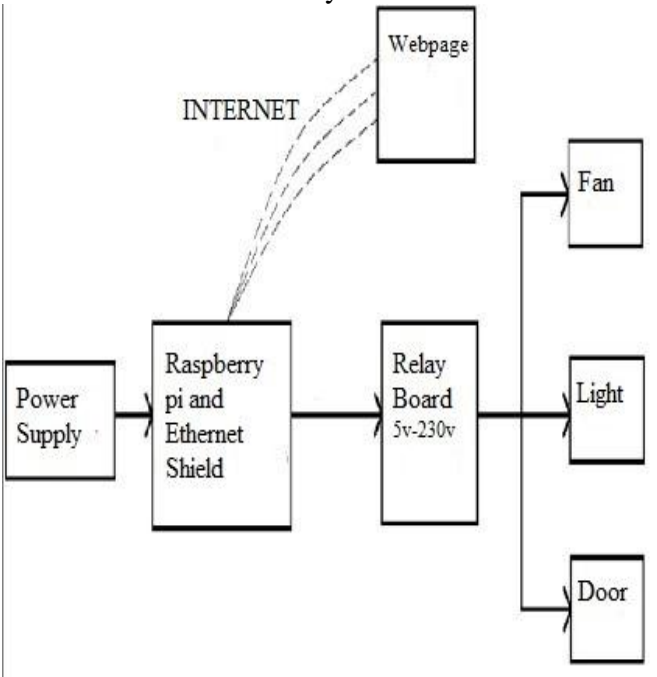

The IOT-based design gives abnormal state flexibility for the correspondence and data. It is the approach which is significant in a wide range of sorts of situations, for example, patient monitoring systems, security, and controlling the different applications. The IOT venture intends to draw the distinctive odds of using Internet Protocol v6 and remaining checks to vanquish the shortcomings using the IoT. The IOT extends for the most part exhibit a dominating and escalated investigation of each and every sensible functionalities, instruments and diverse conventions that can likewise be used for the working of IOT structures however the interconnections may occur between all very surprising IOT applications.

This type of solutions will be able to improve strategic advantages to mature economies, and as new business models and techniques can leverage those technological solutions providing rooms for the economic development.

Some shields communicate with the help of Raspberry pi board directly over an array of pins, but a set of shields is independently addressable via an $\mathrm{I}^{2} \mathrm{C}$ serial bus so several shields can be stacked and used in parallel.

\section{Conclusion}

These days, a lot of consideration is being given to IOT in many fields. It chiefly manages the correspondence between a few electrical gadgets. The IOT is encountering quick reception in the public, from mechanical to home applications. We can influence gadgets to convey through an interconnection organize. We can apply the idea of IOT many fields. Here, we are for the most part focusing on controlling Home Machines. As per condition, consequently, the gadgets can do their errands. With the improvement of the social economy, a number of machines which always increasing have been exhibited in a house. It is an issue that how to oversee and control these apex different machines proficiently and advantageously in order to get more agreeable, security and solid space at home. In current Venture, We will manage a few parts of the IOT in Home Machines controlling.

\begin{tabular}{|l|l|l|}
\hline & Arduino & Raspberry \\
\hline Memory & $0.002 \mathrm{MB}$ & $512 \mathrm{MB}$ \\
\hline Clock Speed & $16 \mathrm{MHZ}$ & $700 \mathrm{MHZ}$ \\
\hline On-board Network & None & Ethernet \\
\hline Multitasking & No & Yes \\
\hline Flash & $32 \mathrm{~KB}$ & SD card (2 to 16 GB) \\
\hline USB & 1 (Only input) & $\begin{array}{l}\text { 2(Peripherals can } \\
\text { connect) }\end{array}$ \\
\hline IDE & Only Arduino & $\begin{array}{l}\text { Anything with Linux } \\
\text { support }\end{array}$ \\
\hline Video Out & Not Available & HDMI, Composite \\
\hline Audio Out & Not Available & HDMI, Analog \\
\hline $\begin{array}{l}\text { Programming Lan- } \\
\text { guages }\end{array}$ & c++ & Python, C \\
\hline Architecture & 8 bits & 32 bits \\
\hline Wi-Fi & - & $\begin{array}{l}\text { Inbuilt(Latest Ver- } \\
\text { sion) }\end{array}$ \\
\hline
\end{tabular}

\section{References}

[1] G. Kortuem, F. Kawsar, D. Fitton, and V. Sundramoorthy,"Smart objects as building blocks for the internet of things,"Internet Computing, IEEE, vol. 14, pp. 44-51, 2010.

[2] S. Hilton. (2012, 14 January). Progression from M2M to the Internet of Things: an introductory blog. Available:http://blog.boschsi.com/progression-from-m2m-to-internet-of-things-anintroductory-blog/

[3] C.-H. Chen, C.-C. Gao, and J.-J. Chen, "Intelligent Home Energy Conservation System Based On WSN," presented at the International Conference on Electrical, Electronics and Civil Engineering, Pattaya, 2011.

[4] R. Piyare and M. Tazil, "Bluetooth based home automationsystem using cell phone," in Consumer Electronics (ISCE), 2011 IEEE 15th International Symposium on, 2011, pp.192-195.

[5] Wikipedia. (2012, 12th December). Home automation.Available: http://en.wikipedia.org/wiki/Home_automation 